\title{
Sources of news as a necessity for improving community health literacy about COVID-19
}

\author{
Seyed Mohammad Hashemi-Shahri ${ }^{1}$, Mohammad Khammarnia*1미, Alireza Ansari-Moghaddam ${ }^{1}$, \\ Fatemeh Setoodehzadeh ${ }^{1}$, Hassan Okati-Aliabad ${ }^{1}$, Mostafa Peyvand ${ }^{1}$
}

Received: 15 Apr 2020

Published: 17 Jun 2020

\begin{abstract}
Background: In the 21st century, the world has become a global village and a disease outbreak in one part of the world can spread rapidly to other countries far away.

Methods: The emergence of the new Coronavirus (COVID-19) in China in January 2020 and its growing level of spread and severity between and within other countries as well as different continents has become a global emergency. Moreover, low health literacy results in more problems and continuation of the outbreak. Consequently, COVID-19 pandemic may produce new debates, discussions, and disturbing developments every day. In the meantime, cyberspace plays an important role in this case.

Results: Improving people's health literacy can lead to increased potential of patients to make informed decisions, reduce health risks, increase disease prevention, and improve quality of life.

Conclusion: The experience during COVID-19 pandemic has shown that health literacy plays an important role in preventing and controlling diseases and pandemic.
\end{abstract}

Keywords: COVID-19, Health literacy, Sources of news

Conflicts of Interest: None declared

Funding: None

*This work has been published under CC BY-NC-SA 1.0 license.

Copyright $\bigcirc \underline{\text { Iran University of Medical Sciences }}$

Cite this article as: Hashemi-Shahri SM, Khammarnia M, Ansari-Moghaddam A, Setoodehzadeh F, Okati-Aliabad H, Peyvand M. Sources of news as a necessity for improving community health literacy about COVID-19. Med J Islam Repub Iran. 2020 (17 Jun);34:63. https://doi.org/10.47176/mjiri.34.63

\section{Editorial}

In the $21^{\text {st }}$ century, the world has become a global village due to pervasive technological advances by which everyone could be affected (1). Accordingly, globalization has led to rapid changes and developments in all dimensions of life, such as economic, culture, and social (social relations decentralization, removal of geographical boundaries, and formation of the so-called network society (2). Similarly, the globalization of public health led to the development of international health diplomacy and international regimes for public health has been introduced in the last century(3). Therefore, in such a global village, a disease outbreak in one part of the world can spread rapidly to other countries far away. For example, the emergence of COVID-19 in January 2020, when China was about to celebrate its New Year, and its growing level of spread and severity between and within other countries and different continents has become a global emergency (4). According to the report from the World Health Organization (WHO), COVID-19 has nearly affected 210 countries with more than 3485936 cases internationally until late April 2020 (5). The spread of the virus has had a substantial effect on the world economy and living conditions of people worldwide (6). High speed of virus propagation, short- term infection rate, and the lack of vaccines and a definitive treatment have faced countries with huge number of challenges in various fields, eg, numerous affected cases and their families, and health, economic, political, and social problems related to this pandemic.

Some of these challenges are directly and indirectly related to people's information. Indeed, the right information at the right time and to the right audience can solve or decrease some of these challenges (4). Moreover, low health literacy results in more problems and continuation of the outbreak (7). Then, in the recent pandemic some people did not behave appropriately and followed medical advices in

Corresponding author: Dr Mohammad Khammarnia, khammarnia@zaums.ac.ir

1. Health Promotion Research Center, Zahedan University of Medical Sciences, Zahedan, Iran 
an unusual and ineffective ways, such as consuming alcohol, neglecting individual health, release of contaminated masks and gloves into the environment, and the consumption of fake products. Thus, considering information sources, the type of information dissemination, and the skills needed to categorize more information is of paramount importance. This paper aims to identify the sources of information, the importance of health literacy, and skills needed to understand correct or incorrect information.

COVID-19 pandemic may produce new debates, discussions, and disturb developments every day. Many people are now living with neurological symptoms and mental confusion, which could provide fertile ground for reports and conspiracy theories to go viral (6). In the meantime, cyberspace plays a highly important role in this case. Cyberspace is a virtual geography created by information and communications technology (ICTs), in which the internet is a remarkable fusion of information types, media, and operators, and thus more material and information are generated. The increasing use of the internet and its applications is also perceptible in interrelationships between societies (8). One of the significant functions of cyberspace and social media is social cohesion. The rapid expansion of mass media, and in particular cyberspace, is one of the factors affecting public health (9). On the other hand, inappropriate use of cyberspace can also severely damage people's knowledge, attitude, behavior, and thus their health. In Corona virus pandemic, people hear from various sources about health care and health-related practices, some of which are neither scientific nor helpful. In addition, multiple sources of information that in some cases provide contradictory material may confuse people. In such situations, governments and health systems should cope with the problems caused by the virus, protect people against it, and fight against artificial reports circulating in the society and the cyberspace. We have experienced that some fraudsters seek to spread rumors and disseminate fake images, videos, and messages in the cyberspace and the community in various ways to raise public concern. Likewise, some people may encourage others by inappropriate advertisements to buy their ineffective and unproven products for disease prevention. For example, some fraudsters sell industrial alcohols (methanol) instead of oral alcohol and persuade people to consume it to prevent the disease, which has resulted in disability or death.

Protection of human health against diseases and crises more than anything requires awareness and enhancements of the health literacy in societies. Improving health literacy can lead to increased potential of patients to make informed decisions, reduce health risks, increase disease prevention, improve physical and mental security, and improve quality of life, and quality of care (7). High health literacy enables individuals to properly interpret and analyze issues, crises, and challenges that are particularly relevant to their health. People can also take better care of themselves and their family against the virus. The spread of the Coronavirus is becoming a global pandemic; thus, health literacy should become a necessity and be assessed in societies, because the community's fear of the Coronavirus cannot be denied, the fear that comes from people's ignorance about the virus
(10).

To prevent Corona virus and promote health literacy, some international organizations have made comprehensive efforts. WHO has released accurate information on disease prevention measurements by holding regular meetings and informing the public through websites and mass media (5). Correspondingly, more countries have made some efforts to fight COVID-19. For instance, the government of Singapore has established an official page and communication software that provides daily updates news to its subscribers to keep the public updated on the latest outbreak data and combat rumors and fake news (11). The Ministry of Health and Medical Education (MOHME) of Iran have started screening all its residents via a telephone number (+98 4030) and a website (salamat.gov.ir). According to the MOHME data, roughly all Iranian population (about 80 million) had been screened in about a month by the mentioned systems.

Institutionalizing health behaviors and providing the necessary training to the public about the current pandemic trend and preventive methods of the disease (e.g., personal health, stay at home, avoiding family gatherings and ceremonies, strengthening information and education campaigns, and using telemedicine system capacity, will definitely decline the trend of the pandemic in the shortest time (4).

Regardless of the unfortunate consequences of Coronavirus outbreak, it could be an opportunity to assess and improve health literacy. Generally, the Coronavirus pandemic in the world will not be the first and last crisis and people and governments need to learn how to manage these crises or emergencies. The experience during this pandemic has shown that health literacy plays an important role in preventing and controlling diseases and pandemics. The right educational models can bring the least material and spiritual cost to a community. In these behavioral models, information producers and disseminators, including the media, government officials, professionals in various fields (physicians, nurses, psychologists etc.) and even people, should be taken into account. Media and information professionals with the necessary knowledge about the production and dissemination of organized information can play an essential role in coping with crises and unexpected events. Information literacy training and explaining appropriate behaviors in crisis are also effective in prevention (12).

In general, by increasing people's health literacy level and improving their knowledge of information resources and cyberspace, health systems could take effective steps towards control of COVID-19. Thus, influential organizations, such as state media, educational institutions, health departments etc., should take necessary measures to improve the public's health literacy. Also, governments and families are recommended to control information resources and prevent the spread of infodemic in cyberspace to prevent the pandemic.

\section{Conflict of Interests}

The authors declare that they have no competing interests. 


\section{References}

1.Dehghanbanadaki H, Seif F, Vahidi Y, Razi F, Hashemi E, Khoshmirsafa M, et al. Bibliometric analysis of global scientific research on Coronavirus (COVID-19). Med J Islam Repub Iran. 2020;34(1):354-362.

2. Chelysheva I, Mikhaleva G. Life in a global village and principles on tolerance: the role and value of Marshall McLuhan's legacy. Media Edu. 2019;59(2):224-229

3. Fidler DP. The globalization of public health: the first 100 years of international health diplomacy, in Global Health. 2017, Routledge. p. $125-132$.

4. Arashiro T, Furukawa K, Nakamura A. COVID-19 in 2 Persons with Mild Upper Respiratory Symptoms on a Cruise Ship, Japan. Emerg Infect Dis. 2020;26(6).

5. World Health organization, Coronavirus disease (COVID-2019) situation report-. 2020. available from: https://www.who.int/ emergencies/diseases/novel-coronavirus-2019/situation-reports

6. Ali I. The COVID-19 Pandemic: Making Sense of Rumor and Fear: Op-Ed. Med Anthropol. 2020:1-4.

7. Asmundson GJ, Taylor S. How health anxiety influences responses to viral outbreaks like COVID-19: What all decision-makers, health authorities, and health care professionals need to know. J Anxiety Disord. 2020;71:102211.

8. Zhang L, Du HR, Zhao YN, Wu RW, Zhang X. Urban networks among Chinese cities along" the Belt and Road": A case of web search activity in cyberspace. PloS One. 2017;12(12).

9. Nazari H, Bakhtiar K, Hosseinabadi R. A Survey of lifestyle influenced by Cyberspace and its impact on mental health (Case Study University of Medical Sciences in 2015). Yafte. 2017;19(4).

10. Goyal K, Chauhan P, Chhikara K, Gupta P, Singh MP. Fear of COVID 2019: First suicidal case in India. Asian J Psychiatry. 2020;49:e101989-e101989.

11. Mohsina N. Global Health Security-COVID-19: Trying Times for Singapore's Social Resilience. Rsis Edu. 2020;31. Available from: https://www.rsis.edu.sg/rsis-publication/cens/global-health-securitycovid-19-trying-times-for-singapores-socialresilience/\#.Xs4RjRozYdU

12. Cowling BJ, Leung GM. Epidemiological research priorities for public health control of the ongoing global novel coronavirus (2019nCoV) outbreak. Eurosurveillance. 2020;25(6). 